\title{
LITERATURA E FILOSOFIA: Bakhtin e Umberto Eco, intertextualidade e dialogismo na obra "O Nome da Rosa"
}

\author{
LITERATURE AND PHILOSOPHY: Bakbtin and Umberto Eco, intertextuality and dialogism in the \\ work "The name of the Rose"
}

\section{Cristiano Dias Da Silva ${ }^{1}$}

Resumo: O presente artigo tem como objetivo estudar e compreender o conceito de intertextualidade (dialogismo) em Mikhail Bakhtin e Umberto Eco enfatizando possíveis pontos de convergência/divergência entre os dois autores. Nesse sentido, o estudo em questão examina a origem do conceito de dialogismo em Bakhtin que com os estudos de Kristeva passa a ser visto como intertextualidade. Por sua vez, Eco quando estuda a intertextualidade e a desenvolve na prática em seus romances, como por exemplo, "O Nome da Rosa" retoma a ideia de dialogismo de Bakhtin e o conceito de intertextualidade de Kristeva. Mas, em Eco intertextualidade deve ser compreendida dentro da teoria literária pós-moderna como também em relação a sua ampla teoria da interpretação semiológica. Assim, em Eco a intertextualidade se enriquece com novas conotações, principalmente em relação aos conceitos de "enciclopédia cultura" e "mundos possíveis" que se dialogam com as noções de interdiscursividade e dialogismo de Bakhtin.

Palavras-chave: intertextualidade, dialogismo, pós-modernidade, enciclopédia cultural, mundos possíveis.

\begin{abstract}
This article aims to study and understand the concept of intertextuality (dialogism) in Mikhail Bakhtin and Umberto Eco, emphasizing possible points of convergence / divergence between the two authors. In this sense, the study in question examines the origin of the concept of dialogism in Bakhtin, which with Kristeva's studies comes to be seen as intertextuality. In turn, Eco when he studies intertextuality and develops it in practice in his novels, such as "O Nome da Rosa" takes up Bakhtin's idea of dialogism and Kristeva's concept of intertextuality. But, in Eco intertextuality it must be understood within the postmodern literary theory as well as in relation to its broad theory of semiological interpretation. Thus, in Eco, intertextuality is enriched with new connotations, especially in relation to the concepts of "cultural encyclopedia" and "possible worlds" that are in dialogue with Bakhtin's notions of interdiscursivity and dialogism.
\end{abstract}

Keywords: intertextuality, dialogism, postmodernity, cultural encyclopedia, possible worlds.

\section{INTRODUÇÃO}

Em setembro de 2020 completam-se 40 anos do lançamento de uma das grandes obras da literatura da pós-moderna: O Nome da Rosa², esta obra foi estudada em seus vários aspectos, porém

\footnotetext{
${ }^{1}$ Professor - Instituto Federal do Sertão Pernambucano. Mestre em Filosofia, Doutorando da Universidade Estadual do Rio Grande do Norte UERN - Pau dos Ferros-RN. crist200@hotmail.com.

${ }^{2}$ Inserida na literatura pós-moderna e conhecido mundialmente o romance "O Nome da Rosa" foi recebido com entusiasmo na Itália em sua publicação em 1980, logo vendeu 500 mil copias por lá e obteve três prêmios literários no ano seguinte. Foi rapidamente traduzido para o alemão, francês, inglês e diversas outras línguas tornando-se best seller mundial”. (LODGE, 2018, p 10). Hoje após quarenta anos de sua publicação, de acordo com Franchi (2018) desenvolver qualquer estudo sobre esta obra é uma tarefa extremamente árdua: analisando a lista das resenhas, teses
} 
enfatizaremos apenas o problema da intertextualidade na relação Umberto Eco ${ }^{3}$ e Mikhail Bakhtin ${ }^{4}$. Tendo sua origem no ambiente literário, o termo intertextualidade adquiriu diversas definições na contemporaneidade principalmente em ambiente da própria teoria literária. Nosso primeiro objetivo, portanto, será apresentar o sentido do termo intertextualidade-dialogismo, originário na teoria bakhtiniana; e, em um segundo momento se focará sobre o sentido de intertextualidade em Umberto Eco considerando a obra "O Nome da Rosa". Por fim, veremos as inter-relações possíveis entre o dialogismo de Bakhtin na teoria da interpretação de Eco.

A base teórica que perpassa este trabalho é a análise do texto. Logo, partimos das ideias dos próprios autores (Eco, Kristeva e Bakhtin) com o intuito de extrair possíveis interpretações dentro da teoria intertextual da pós-modernidade. Nas sublinhas do texto estar também às influências da teoria semiótica e semiológica como entendido por Pierce (2005) e Saussure (2012).

Assim, destacamos que o embate entre o dialogismo e a intertextualidade apresenta uma serie de resultados passíveis de corroboração ou não a partir da análise do texto literário. O primeiro deles é evolução cognoscível do termo dialogismo que vai se ampliando como uma teoria interpretativa partindo de Bakhtin até Eco. Em seguida, enfatizamos as contribuições de Eco em ampliar a significação de intertextualidade com os conceitos de "enciclopédia mundo" e "leitor modelo”. Surgem ainda outros resultados não esperados apriori como a interligação do intertexto com a semiótica. Por ultimo, o intertexto com a ironia revaloriza o passado e apresenta conotações entre o contexto medieval do século XIV e a pós-modernidade, observando que entre a questão dos universais ${ }^{5}$ e a semiologia intertextual há uma linha de evolução fértil na interpretação do texto.

\section{AS ORIGENS DA TEORIA INTERTEXTUAL EM BAKHTIN}

Dificilmente se pode falar de intertextualidade em Bakhtin sem referimento a Julia Kristeva. Segundo Bernardelli (2010), Kristeva em seu ensaio "Semiótica: introdução à semanálise", tinha como objetivo introduzir a monografia tão recente traduzida para o francês da obra de Bakhtin: Problemas

\footnotetext{
de doutorado e dos ensaios que nos últimos dez anos foram produzidos em torno de Guglielmo da Baskerville e de Adso da Melk, já é suficiente para colocar-nos num estágio de vertigens borgesiano.

${ }^{3}$ Umberto Eco (1932-2016) nasceu em Alexandria, Piemonte, Itália, no dia 5 de janeiro de 1932. Estudou Filosofia e Literatura na Universidade de Turim, onde mais tarde tornou-se professor.

${ }^{4}$ Mikhail Bakhtin (1895-1975) nasceu em Oriol, Rússia. Foi um filósofo e pensador russo, teórico da cultura europeia e das artes, um verdadeiro pesquisador da linguagem humana. Seus estudos inspiraram trabalhos de estudiosos das mais diversas áreas.

5 A questão dos universais pode ser entendida pela disputa entre nominalistas e realistas. Existem variações de nominalistas e realistas em relação à interpretação dos no nomes texto e no discurso dos mais radicais aos moderados, segundo ( REALE, 2011, p. 169) "para o nominalismo o universal seria simples nome que indica uma multiplicidade de indivíduos e nada mais. Não apenas não tem um status ontológico, mas também não tem um status lógico fundativo da palavra". Por outro lado o realismo "afirma que os universais existem em si, como ideias platônicas, ou seja, ante rem, antes das coisas. Assim como as ideias arquétipos são modelo da realidade, o conhecimento delas é indiretamente o conhecimento da realidade" (REALE, 2011, p.166).
} 
da obra de Dostoievski $i^{6}$; na qual Bakhtin introduzia algumas categorias de análise para obras literárias como dialogismo ${ }^{7}$ e polifonia ${ }^{8}$.

Para além da controvérsia da origem do termo propomos uma compreensão da intertextualidade partindo da interpretação dada por Knezevic (1988), onde ela identifica em primeiro lugar duas grandes linhas da teoria romanesca europeia para compreender o dialogismo bakhtiniano, uma vez que, através dos estudos de Kristeva se originou o termo intertextualidade. A primeira linha de interpretação parte do "diálogo socrático, perpassa pela menopeia para atingir seu auge no romance polifônico de Dostoievsky" (KNEZEVIC,1988, p. 3, tradução nossa) ${ }^{9}$ e, é exatamente nesta linha de pensamento que se constrói o dialogismo do discurso em Bakhtin. $\mathrm{O}$ contrário disso seria toda tradição de pensamento construída para interpretar o romance apenas como gênero monológico.

Nesse sentido, o texto narrativo apresenta como uma de suas caraterísticas o dialogismo ${ }^{10}$, considerado como ponto de vista heterogêneo, onde autor ou narrador perdem suas autonomias em formular sua finalidade, isto é, não são mais uma influência definitiva e monopolista das vozes. Essa nova possibilidade de existir das vozes evidenciadas por Bakhtin permite ao texto de exibir em um mesmo plano, uma tensão constante entre polos opostos trazendo dinamismo e criatividade à velha dialética socrática. Surgem então, duas repercussões de plano temático diferentes: por um lado, "a menipeia da natureza relativa e ambivalente dos contrários", por outro, "aquele estilístico uso das figuras como oxímoro e antítese”. (KNEZEVIC,1988, p. 3). É nesse sentido que afirma Bernardelli:

[...] partindo da obra de Dostoievski, Bakhtin individuava particulares formas discursivas nas quais podiam ser identificadas a presença de diversas 'vozes' ou subjetividades. Em um mesmo discurso ou texto era possível individuar duas

\footnotetext{
${ }^{6}$ Para Bernardelli (2010) a primeira versão foi publicada como ensaios com o titulo de problemas da obra de Dostoievski, em 1963 Bakhtin reelabora a obra e publica com o titulo de Problemas da poética de Dostoievski.

7 “[...] o dialogismo é o modo de funcionamento real da linguagem, é o princípio constitutivo do enunciado. Todo enunciado constitui-se a partir de outro enunciado, é uma réplica a outro enunciado. Portanto, nele ouvem-se sempre, ao menos, duas vozes. Mesmo que elas não se manifestem no fio do discurso, estão aí presentes" (FIORIN, 2011, p. 13).

${ }^{8}$ Para BEZERRA (2014) polifonia se define pela convivência e pela interação, em um mesmo espaço do romance, de uma multiplicidade de vozes e consciências independentes e imiscíveis, vozes plenivalentes e consciências equipovalentes, todas representadas de um determinado universo e marcadas pelas peculiaridades desse universo.

${ }^{9}$ La construzione dialógica del discorso romanzesco, secondo Bachtin, si rivela in primo luogo per il suo inserimento tematico-compositivo in uma delle linee evolutive del romanzo europeo, che inizia col dialogo socratico e prosegue con la menippea, per ragiungere il culmine nell opera polifonica de Destoevskij [...].

10 Vale lembrar que dialogismo é tanto convergência, quanto divergência; é tanto encontro, quanto desencontro; é aderir, quanto recusar; é tanto ajuntar, quanto conflitar; por isso o circulo de Bakhtin entende as relações dialógicas como lugar de conflito entre os enunciados, por fim é um espaço de luta entre vozes de um contexto social FARACO (2003).
} 
diversas 'palavras', duas distintas posições subjetivas que dialogavam implicitamente (BERNARDELLI, 2010, p. 11, tradução nossa) ${ }^{11}$.

Bakhtin vai além da tradição típica do dialogo socrático, pois dialógica não é apenas a distribuição das vozes e dos personagens romanescos, mas também o resultado do uso da palavra narrativa ao outro em novo contexto. Porém é preciso cuidado para não banalizar essa estruturação bakhtiniana em duas vozes, ela não é apenas um usufruir de parágrafos do texto do outro. O texto deve ser visto com reservas e certas condições, pois "contem o que é do outro", deve-se assumir a responsabilidade concernente "ao estilo, ao ponto de vista narrativo e ao grau de parcialidade ou empenho ideológico". (KNEZEVIC,1988, p. 4).

É nesse direção que aparece a problemática dos ideologemas na teoria da interpretação de Bakhtin. A multiplicidade de vozes presente no discurso carregam em si posições diversas de “ideologias e pensamentos" como expressões, conceitos ou citações "que pela forte identificação ideológica foram definidas por Bakhtin de ideologemas" (BERNARDELLI, 2010, p. 12). Mas, o que são então os ideologemas? São sinais ou indícios da presença de uma posição ideológica ou discursiva, são os vestígios. Dessa forma, são exatamente essas diversidades de vozes, de dialogo no texto literário que leva Bakhtin a falar de polifonia e, por conseguinte, chegar à ideia de intersubjetividade que na concepção de Kristeva ${ }^{12}$, seria a intertextualidade já latente, mais ainda não tão explicitada, na teoria de Bakhtin:

Não são mais verdadeiros sujeitos a dialogar no romance polifônico - não são singulares e bem identificáveis personagens -, mas apenas 'vozes' ou textos, são palavras, expressões e fragmentos de discursos que remete-nos a uma certa origem ou fonte ideológica. (BERNARDELLI, 2010, p. 11-12, tradução nossa) ${ }^{13}$.

As diferentes posições ideológicas presentes no discurso literário são evidenciadas pelas vozes e palavras singulares apresentadas na diversidade linguística, como dialetos e línguas nacionais. Nesse sentido, um dos dispositivos narrativos é o plurilinguíssimo onde se definem uma pluralidade de vozes e opiniões, de culturas, e de visões de mundos. Um texto do romance: O Nome da Rosa de Umberto Eco pode exemplificar como "a comunicação linguística pode caracterizar uma

\footnotetext{
${ }^{11}[$ [...] partendo dalle opere di Dostoevskij -, Bachtin individuava delle particolari forme discorsive in cui poteva essere identificata la compresenza di diverse "voci" o soggettività. In uno stesso discorso o testo, secondo Bachtin era possibile individuare due diverse "parole", due distinte posizioni soggettive che dialogavano implicitamente.

12 "A semioticista diz que, para o filósofo russo, o discurso literário não é um ponto, um sentido fixo, mas um cruzamento de superfícies textuais, um diálogo de várias escrituras, um cruzamento de citações. Como ela vai chamar "texto" o que Bakhtin denomina "enunciado", ela acaba por designar por intertextualidade a noção de dialogismo. Roland Barthes difundiu o pensamento de Kristeva e, a partir daí, o termo intertextualidade" passa a substituir a palavra dialogismo. "Qualquer relação dialógica é denominada intertextualidade". (FIORIN, 2011, p. 22).

13 "Non sono più dei veri soggetti a dialogare nei romanzi polifonici - non sono singoli e ben identificati personaggi -, ma solo "voci" o "testi", sono parole, espressioni e frammenti di discorso che rinviano ad una certa origine o fonte ideologica".
} 
implícita polêmica histórica e ideológica” (BERNARDELLI, 2010, p.13). Vejamos o trecho a seguir:

Penitenciagite! Vide quando draco venturus est para rodegarla a tua alma! A mortz est super nos! Implora que venha o santo papa para livrar-nos a malo de todos le peccata! Ah, ah, gostais d'ista necromancia de Domini Nostri Iesu Christi! Et mesmo jois m'es dols e plazer m'es dolors... Cave el diablo! Semper m'espreita em qualquer canto para me ferrar os calcanhares. Mas Salvador non est insipiens! Bonum monasterium, e aqui se manja e se roga dominum nostrum. Et el resto valet um figo seco. Et amen. No? (ECO, 2018, p. 84).

Neste texto o dialogo parte de Salvatore que adverte o jovem Adso com as confusas palavras apenas citadas. Por isso mesmo, Adso, o cronista do romance diz que - "Salvatore fala todas as línguas e nenhuma" - pois Salvatore em sua vida perambulando pela Europa tinha recolhido retalhos de vários dialetos ${ }^{14}$ "aqueles itálicos, o provincial, o catalão e tantos outros; unindo ao latim da missa e da pouca Bíblia que aprendeu.” (BERNARDELLI, 2010, p. 13).

Apesar da confusão e simplicidade das palavras de Salvatore elas evidenciam uma grande descoberta: são ideologemas, fruto da sua história de vida, do seu contexto social, elas estão impregnadas de uma rica significação ${ }^{15}$. Penitenżiate! Explicita uma história de vida feita de heresia e perseguições; vida sem liberdade, amargada sob a imposição doutrinária ditada pelo latim simples et amem; experiência evidenciada ainda por cosmologias e teologias adulteradas e deturbadas gostais d'ista necromancia de Domini Nostri Iesu Christil. Por fim, a babel linguista de Salvatore deixa claro o conflito existente, "demonstra intercessão de vozes e o conflito de diversos discursos" que exemplificam o dialogismo e a polifonia (BERNARDELLI, 2010, p. 12-13).

\section{A INTERTEXTUALIDADE EM UMBERTO ECO}

Para entender a intertextualidade na perspectiva equiana, principalmente considerando sua obra mais conhecida Il Nome della Rosa, nada mais propício que destacar as declarações do próprio Eco no seu "Postille a Il nome della rosa". Neste, segundo Knezevic (1988), Eco individua duas características da materialidade narrativa. Por um lado, tal materialidade "tem suas próprias leis

\footnotetext{
${ }^{14}$ Salvatore apresenta seu discurso retirando a diversidades de palavras da enciclopédia (mundo e experiências vividas). Mais adiante explicaremos a noção de enciclopédia e mundos possíveis em Eco e como essas noções são interligadas com a interdiscursividade e o dialogismo de Bakhtin.

15 Vale lembrar que os diálogos dos personagens de Eco são imbuídos de teorias semióticas e semiológicas dentre outras de Pierce (2005) e Saussure (2012). Este tipo de estudo será desenvolvido em outro expediente.

16 "Pós-escrito a "O Nome da Rosa", teve sua primeira versão publicada em alfabeta, 49, junho de 1983 nele Eco faz uma apresentação dos principais temas de sua obra.
} 
naturais" e de outro, "traz consigo a lembrança da cultura que carrega (o eco da intertextualidade)"17. A expressão 'eco da intertextualidade' se aplica ainda a duas classes de fenômenos que pavimentam o texto: os primeiros são efeitos da descoberta que "os livros falam sempre de outros livros e que toda história conta uma história já contada" (ECO, 2018, p. 536). No desenvolver do romance esta ideia é reafirmada na conversa entre os personagens Adso da Melk e Guilherme de Baskeville:

Adso - Como assim? Para saber o que diz um livro deveis de ler outros? Guilherme - Às vezes pode-se proceder assim. Frequentemente os livros falam de outros livros. Frequentemente um livro inócuo é como uma semente, que florescerá num livro perigoso, ou ao contrário, é o fruto doce de uma raiz amarga. Não poderia, lendo Alberto, saber o que poderia ter dito Tomás? Ou, lendo Tomás, saber o que terá dito Averroes? (Eco, 2018, p.318)

No caso de $O$ Nome da Rosa o enxerto intertextual se dá na criação do texto quando o sujeito da criação de forma estratégica cria uma máscara ${ }^{18}$ atrás de uma instância narrativa (Adso) que depois se multiplica Vallet, Mabillon, Eco redator, que reconstrói o manuscrito confiando na própria memória ${ }^{19}$. O segundo tipo de fenômeno se refere aos elementos constitutivos do personagem Guilherme de Baskeville apresentado como uma porta para citações, através das quais são contados uma série de outros textos, definidas por Eco como "formas de dialogismos intertextuais" (ECO, 1989, p.113).

Partindo dessa abordagem inicial da compreensão do termo intertextualidade na obra O Nome da Rosa percebe-se que a forma como Eco intende este conceito estar também, em muitos aspectos, ligada a compreensão originária do termo elaborado por Kristeva (ECO, 1993, p. 92-166). Aprofundando esse estudo já iniciado anteriormente e agora recolocado no contexto equiano, em

\footnotetext{
17 Colocamos aqui o texto original devido à importância do texto: “[...] esibisce delle proprie leggi naturali” ... "porta con sé il ricordo della cultura di cui è carica (l'eco dell'intertestualità)” (ECO, 2019, p.583). As pequenas citações feitas apresentam diferenças em pelo menos duas obras consultadas em (Eco, 2018, p.533) encontra-se como citado no texto (corpo do trabalho): “[...] tem suas próprias leis naturais" ... "traz consigo a lembrança da cultura que carrega (o eco da intertextualidade)"; já em (Eco, 1985, p.7) “[...] possui suas próprias leis naturais" ... "traz consigo a lembrança da cultura de que está embebida (o eco da intertextualidade)". Não se quer aqui desconsiderar as traduções, mas sim disponibilizar para leitor, quando possível, o texto original. Sobre as nuances da tradução brasileira pode-se consultar (FONDA, 1987 p. 95-105).

18 "Era meu exórdio como narrador e até então eu havia olhado os narradores do outro lado da barricada. Envergonhava-me contar. Sentia-me como um crítico teatral que, de repente, fica exposto às luzes da ribalta e se vê olhado por aqueles de quem, até então, havia sido cúmplice, na plateia. Pode-se dizer 'Era uma bela manhã de fins de novembro' sem sentir-se um Snoopy? E se eu deixasse Snoopy dizer isso? Ou seja, se 'era uma bela manhã...' fosse dito por alguém autorizado a dizê-lo, porque no tempo dele assim que se dizia? Uma máscara, era disso que eu precisava. [...] Estava agora livre de qualquer receio" (ECO, 2018, p. 536).

19 “O 'pós-moderno' pressupõe também, continua Eco, uma concepção diferente do tempo e, consequentemente, um modo particular de significar o conceito de memória e de passado. Segundo a perspectiva da pós-modernidade de que não é mais possível projetar o futuro a partir do presente - projeção que na modernidade assumia muitas vezes traços utópicos e progressistas -, o retorno ao passado passa a ser viável, já que, depois da ruptura com a história e com a tradição feita pelas vanguardas do começo do século XX, não existe mais um limite a ser ultrapassado; em lugar dos "limites a serem vencidos", o que há é uma pesquisa permanente em uma espécie de banco de dados "de estilos todos contemporâneos" (JAMESON, 2007) que pode ser acessado a todo momento” (AGAZZI; VINCI, 2012, p. 84).
} 
1976 a psicanalista e crítica literária francesa de origens búlgara publica seu ensaio Bachtine, le mot, le dialog, le roman ${ }^{20}$.

[...] todo texto se constrói como um mosaico de citações, todo texto é absorção e transformação de outro texto. Em lugar da noção de intersubjetividade, instalase a de intertextualidade, e a linguagem poética lê-se pelo menos como duplo (KRISTEVA, 2005, p. 68).

Eco faz diversas referências ao termo intertextualidade cunhado por Kristeva, principalmente nos estudos sobre "seleções contextuais e circunstâncias", "inferências baseadas em quadros intertextuais" e "os passeios inferenciais" (ECO, 1993, p. 110-166) ${ }^{21}$. Por sua vez, quando Kristeva fala de intertextualidade estar se referindo também a dois pais escondidos do termo Mikhail Bakhtin (1895-1974), o qual já foi feito algumas explanações sobre a origem do dialogismo e intertextualidade, e Ferdinand de Saussure (1857-1913) que não será estudado neste trabalho.

Além da apresentação do termo ter sido feita pelo próprio Eco no Postille e das conexões com o sentido de intertextualidade de Kristeva, deve-se ainda considerar que em Eco o conceito de intertextualidade precisa ser compreendido dentro de dois aspectos: o contexto literário e a cultura da pós-modernidade, e ser ambientado e compreendido dentro do contexto da sua ampla teoria da interpretação do texto. Nesse sentido, a figura do leitor é fundamental na ativação do texto, pois para Eco o texto "é como uma máquina preguiçosa que precisa ser ativada pelo leitor", o sentido do texto depende da função fundamental do leitor (BERNARDELLI, 2010, p. 33).

Um texto mal escrito poderá irritar o leitor enquanto que textos que despertam a curiosidade do leitor e o levam a colaborar com a significação do texto poderá ser uma obra de sucesso. No livro Lector in Fabula, Eco descreve vários possíveis níveis e planos de elaboração do sentido textual criado hipoteticamente por um leitor modelo ${ }^{22}$. Os diversos níveis de análise do

\footnotetext{
20 Os ensaios foram traduzidos para o Português com o título de Semiótica: introdução a semanálise. A temática em que desenvolve o tema da intertextualidade estar no capitulo: a palavra, o diálogo e o romance (KRISTEVA, 2005, p. 6596).

${ }^{21}$ Os textos em que Eco se refere a Kristeva sobre a intertextualidade são os seguintes: $1^{\circ}$ "Con las selecciones contextúales nos introducimos en el sistema de la competencia intertextual, cuyo alcance se verá con más claridad cuando consideremos los cuadros o frames. De todas maneras, suponer que, en contextos teológicos, la expresión |verbo| no debe interpretarse como categoría gramatical, sino como "segunda persona de la santísima trinidad", significa que no puede haber uma representación enciclopédica de um lexema sin que se evoquen los usos de ese lexema en textos precedentes" (ECO, 1993, p. 110).

$2^{\circ}$ "Ningún texto se lee independientemente de la experiencia que el lector tiene de otros textos. La competencia intertextual representa un caso especial de hipercodificación y establece sus propios cuadros. (ECO, 1993, p. 115).

$3^{\text {o }}$ "En efecto: activar un cuadro (sobre todo si es intertextual) significa recurrir a un topos. A estas salidas del texto (para volver a él cargados com un botín intertextual) las denominamos paseos intertextuales” (ECO, 1993, p. 166).

22 "A temática sobre o leitor-modelo comparece basicamente no ensaio O leitor-modelo, presente no livro Lector in fabula. Ao discutir de início o papel do leitor nos textos narrativos, Eco começa considerando a incompletude do texto.
} 
texto sugere que o leitor faça saltos fora do texto, isto é ligar o texto lido com diversos outros textos, Eco definiu essa habilidade do leitor de "competência intertextual". (BERNARDELLI, 2010, p. 34).

É nesse sentido que em O Nome da Rosa Eco faz através da intertextualidade uma ligação entre diversos períodos filosóficos com autores e ideias diferentes que apenas será regozijada pelo leitor modelo capaz de fazer a ligação com diversos outros textos e perceberá a existência de outras filosofias modernas e contemporâneas (pós-modernidade) nos diálogos criados pelo autor. Portanto, é nesse hibridismo de voltar ao passado filosófico medieval com um olhar pós-moderno que Eco relata:

\begin{abstract}
"eu queria escrever um romance histórico [...] Não sei até que ponto fui fiel a esse proposito. Não creio ter deixado de cumpri-lo quando mascarava citações de autores posteriores (como Wittgenstein) fazendo-as passar por citações da época. Nesses casos, eu sabia muito bem que não eram os meus medievais que eram modernos, mas sim os modernos que pensavam como medievais. Pergunto-me se $a \square$ s vezes não emprestei aos meus personagens fictícios uma capacidade para, a partir dos disiecta membra de pensamentos puramente medievais, compor alguns unicórnios conceptuais que, enquanto tais, a Idade $\mathrm{Me} \square$ dia na $\square$ o reconheceria como seus. Creio que um romance histórico deva também fazer outra coisa: não apenas identificar no passado as causas do que aconteceu depois, mas também desenhar o processo pelo qual essas causas foram lentamente produzindo seus efeitos" (ECO, 2018, p. 558-559).
\end{abstract}

Por outro lado, as competências intertextuais são muitas e flexíveis, elas dependem da cultura, da educação, dos hábitos de leitura e são estes hábitos que definirão o gosto e o prazer de leituras, pois obras e gêneros que fazem parte de sua competência intertextual deixa o leitor numa zona de conforto, principalmente os leitores menos exigentes. Leitores mais semiótico ${ }^{23}$, por sua vez, exigem uma "tempestade intertextual", são leitores que querem ser desafiados pelo novo e querem maiores esclarecimentos daquilo que ainda conhecem apenas em parte. Nesse sentido:

Eco constuma distinguir diferentes tipos de leituras, colocando-os entre dois pólos (extremos e ideais) do leitor semântico e do leitor crítico. O leitor semântico é aquele que executa o texto desde o início até o fim aproveitando apenas a trama, do desenvolvimento narrativo da história. Em vez disso, o leitor crítico é aquele usuário ideal que se lança em busca de diversos sentidos textuais, de "duplo codificações "(de um double coding) do texto. O leitor crítico é evidentemente o

Para ele, um texto é incompleto por que pressupõe sempre a colaboração de um destinatário. Um dos fatores da incompletude do texto escrito reside no fato de este ser composto por palavras, frases, termos isolados. Enquanto não correlacionado com referência a um determinado código, ao seu conteúdo convencionado, uma expressão permanecerá puro flatus vocis". (SANTOS, 2007, p. 97).

${ }^{23}$ Em diversos diálogos da obra pode-se encontrar uma analogia do texto com a tríade do raciocínio proposta por Peirce (2005, p 5-13); no seu livro Semiótica "a tríade do raciocínio, a tríade na metafisica e tríade na psicologia deixando claro que o texto pode ter vários caminhos de interpretações a depender do leitor". 
que vai em busca de cadeias intertextuais (BERNARDELLI, 2010, p. 35, tradução nossa) ${ }^{24}$.

Eco chama a competência intertextual do leitor crítico também de "intertextualidade ilimitada" e coloca essa habilidade em prática em seus romances de modo especial em $O$ Nome da $\operatorname{Ros}^{25}$, pois abre a possibilidade para uma cadeia aparentemente interminável de referências de um texto para outro.

O conceito de intertextualidade em Eco apresenta ainda o que chama de novas conotações e colorações. De fato, já em 1977, Eco publica pela primeira vez no Jornal Italiano "L'Espresso" um magnifico texto intitulado Casablanca, o la rinascita degli $d e i^{26}$ que tinha como um de seus objetivos responder a seguinte pergunta: por que um livro ou um filme (ou um objeto da arte) pode se tornar um objeto de culto? Segundo Eco uma produção cultuada é aquela possível de ser "removível" que dá ao seu usuário a possibilidade de "identificar" e "reconhecer" arquétipos. Estes, por sua vez, "são aqueles elementos ou características da narração que todos nós reconhecemos de alguma forma como essencial para a nossa cultura" (BERNARDELLI, 2010, p. 36), são como "pequenos tijolos" de uma construção complexa que é a enciclopédia cultural $^{27}$. Os arquétipos podem ser exemplificados com frases como "Play it again, Sam" ou "Nel mezzo del cammin di nostra vita".

As duas frases citadas no parágrafo anterior pertencentes ao texto de Bernardelli (2010) são de autores de épocas bem diferentes, a primeira de Humphrey Bogart e a segunda de Dante Alighieri para se entender melhor que o conceito de intertextualidade em Eco só pode ser compreendido dentro da noção pós-moderna de cultura ${ }^{28}$. A literatura pós-moderna é aquela forma de narração que precisa considerar toda a tradição, que tem o peso de considerar todo à "memória

\footnotetext{
24 "Eco usa distinguere i diversi atteggiamenti di lettura collocandoli tra i due poli (estremi e ideali) del lettore semantico e del lettore critico. Il lettore semantico è quello che scorre il testo dall'inizio alla fine godendo della sola trama, dello sviluppo narrativo del racconto. Il lettore critico è invece quell'ideale fruitore che si mette alla ricerca di sovrasensi testuali, di "doppie codificazioni”" (di un double coding) del testo. Il lettore critico è evidentemente quello che va alla ricerca di catene intertestuali".

25 "O Nome da Rosa é construído por meio de uma intensa intertextualidade, lida, aqui, como princípio estruturante, uma vez que determina a própria arquitetura, multifacetada, poliédrica, da obra, o que, para Eco, resulta de um intenso e meticuloso trabalho do tecido do romance, cujo resultado final é um sofisticado jogo metatextual" (AGAZZI; VINCI, 2012, p. 96).

${ }^{26}$ Casablanca, ou o renascimento dos deuses Eco (1977).

27 "Eco propõe que em lugar da obra hermeticamente encerrada sobre si mesma, leia-se o que ele chama de romanceenciclopédia, cuja imagem de um saber aberto jamais poderá ser aceito como definitivo, porque os vários níveis de significação podem ser interpretados de incontáveis maneiras. A representação do mundo como uma multiplicidade ilimitada é móvel e sugere inesgotáveis saberes e linguagens e é, também, um mapeamento da vida de uma cultura, entendida como um intrincado de sistemas cujas significações são potencializadas pelas formas narrativas" (AGAZZI; VINCI, 2012, p. 97).

${ }^{28}$ De modo geral para Eco "o Pós-modernismo se organiza enquanto movimento capaz de, em primeiro lugar, situarse criticamente perante os movimentos anteriores, e, sobretudo, perante o lugar da arte e da literatura na cultura, e, em segundo lugar, capaz de articular uma ideologia contestadora; pudemos perceber a importância que os temas ligados à vanguarda como formatividade revolucionária, à institucionalização do Modernismo e ao papel da cultura de massa na institucionalização da vanguarda e do Modernismo têm para a construção de um pensamento crítico acerca da poética pós-modernista". (BRITO, 2006, p. 200).
} 
cultural" e que para sobreviver toda essa exigência deve se valer da ironia ${ }^{29}$. Desse modo, o conceito de "saber" num mundo global possui uma sobrecarga de informação que leva a parecer que "possuir o conhecimento" é algo inatingível. Resta, portanto, "recontar", pois dominar a cultura e o saber aos moldes clássicos tornou-se impossível.

Em O Nome da Rosa Eco se vale da metáfora do medo do riso ou do gênero comedia para mostrar o conflito sempre existente na história entre antigos e modernos ou apocalípticos e integrados. Portanto, o conhecimento cultural, ou a leitura, mesmo carregando o peso do passado, da memória e da tradição, ou seja, exigindo que o leitor seja um fluidor intertextual, jamais poderá se tornar uma atividade apenas hermética, triste e maçante, pelo contrário deve ser vida, divertimento, prazer e riso.

\section{INTERDISCURSIVIDADE, INTERTEXTUALIDADE CULTURAL: POSSÍVEIS PONTOS DE REFERIMENTO ENTRE BAKHTIN E ECO}

Para relacionar e entender a interdiscursividade com a intertextualidade cultural na teoria da interpretação equiana, Bernardelli (2010) apresenta as seguintes perguntas:

[...] de que modo é possível identificar ou definir o intertexto - o texto citado, ausente ou oculto - ao qual é feita referência através do conceito de intertextualidade? Trata-se de um único texto pontual e facilmente identificável ou de algo mais vasto e elusivo? É chamada em causa a memória pessoal do singular fluidor do texto - suas experiências existenciais individuais - ou está em jogo uma diferente e ampla concepção de Memória? (BERNARDELLI, 2010, p. 38 , tradução nossa) $)^{30}$.

Tentaremos apresentar as respostas nos textos seguintes. Utilizando de um modelo já conhecido no campo da semiótica, isto é, o triangulo; Eco utiliza esse símbolo para esclarecer o perigo que se corre ao atribuir de forma incorreta uma relação de dependência entre dois autores. Ele defende que o processo de interpretação deve dar uma atenção especial "as razões da intertextualidade" a intencio intertextualis. Para isso, Eco diz que no triangulo pode ocorrer "uma relação diádica" onde se pode considerar a interpretação entre o autor A e B, mas por trás da

\footnotetext{
29 "Chega um momento em que a vanguarda (o moderno) não pode ir mais além, porque já $\square$ produziu uma metalinguagem que fala de seus textos impossíveis (a arte conceptual). A resposta pós-moderna ao moderno consiste em reconhecer que o passado, $\mathrm{j} \square$ que não pode ser destruído porque sua destruição leva ao silêncio, deve ser revisitado: com ironia, de maneira na $\square$ o inocente" (ECO, 2019, p.554).

30 "Ma in che modo è possibile identificare o definire l'intertesto - il testo "citato", assente o nascosto - a cui si fa riferimento attraverso il concetto di intertestualità? Si tratta di un singolo testo puntuale e ben identificabile oppure di qualcosa di più vasto e sfuggente? Viene chiamata in causa la memoria personale del singolo fruitore del testo - le sue singole esperienze esistenziali -, oppure è in gioco una diversa è più ampia concezione della Memoria?”.
} 
aparente relação entre A e B existe X, que é a cultura. Dessa forma, com a consideração da existência e influência da cultura o nível de interpretação de uma relação diádica que é rígida, fechada e limitada, passa a ser considerada como uma relação triádica, aberta e dinâmica com existência de três elementos no triangulo semiótico.

Nesse sentido, o ponto central em "um relacionamento intertextual não são os dois polos textuais in praesentia, mas um terceiro polo virtual ausente: a enciclopédia cultural" (BERNARDELLI, 2010, p. 49). No que concerne ao conceito de enciclopédia Eco entende que:

A enciclopédia é um postulado semiótico. Não no sentido de que não seja uma realidade semiósica: ela é o conjunto registrado de todas as interpretações, concebíveis objetivamente como a biblioteca das bibliotecas, onde uma biblioteca é também um arquivo de toda a informação não verbal de algum modo registrada, das pinturas rupestres às cinematecas. Mas deve permanecer um postulado porque de fato não é descritível na sua totalidade. As razões por que não é descritível são várias: a série das interpretações é indefinida e materialmente inclassificável; a enciclopédia como totalidade das interpretações contempla também interpretações contraditórias; a atividade textual que se elabora com base na enciclopédia, agindo sobre suas contradições e introduzindo nela continuamente novas segmentações do continuum, também com base em experiências progressivas, transforma com o tempo a enciclopédia, de modo que uma sua ideal representação global, se em algum caso fosse possível, seria já infiel no momento em que estivesse terminada; enfim, a enciclopédia como sistema objetivo das suas interpretações é 'possuída' de maneira diferente por seus diferentes usuários (ECO, 1991, p. 85).

Dessa forma, podemos afirmar que um "mundo possível" tem sua origem em uma enciclopédia cultural, "a enciclopédia contém mundos e regras para construir outros mundos". Ela possui todos os discursos de uma comunidade e colocando-os em relacionamento constrói "uma representação da cultura e da realidade" que é o nosso mundo de referências; portanto, na enciclopédia convivem todas as potencialidades, todos os mundos possíveis de serem construídos com os elementos ou fragmentos discursivos e intertextuais (BERNARDELLI, 2010, p. 49). ${ }^{31}$

Por fim, apresentamos os possíveis pontos de relação entre Bakhtin e Eco: podemos dizer que o conceito de intertextualidade de Eco, principalmente em relação à noção de enciclopédia e mundos possíveis é integrável com a interdiscursividade e o dialogismo de Bakhtin. De fato, a intertextualidade (literária) se abre para uma concepção interdiscursiva de toda a cultura: "a concepção de uma cultura é fundada em um caminho intertextual, em um enredo, entre vários discursos na enciclopédia" (BERNARDELLI, 2010, p. 37). O que acontece na perspectiva

\footnotetext{
31 "Eco propõe o modelo da "enciclopédia", imagem de um saber aberto e jamais definitivo, intertextual e hipertextual, que na interconexão infinita de cada ponto com todos os pontos, possibilita a representação do mundo de modo ilimitado, móvel e portador de saberes e linguagens inesgotáveis, como também permite mapear a vida de uma cultura como um sistema de sistemas intersemióticos interligados.” (TANI,1990 apud AGAZZI; VINCI, 2012, p. 95).
} 
intertextual de Eco é uma ampliação da compreensão em relação a Bakhtin deste conceito de intertextualidade de modo especial quando ele relaciona com a cultura pós-moderna, a ideia de leitor modelo e a noção de enciclopedia mundo.

\section{CONCLUSÃO}

Em vista dos argumentos apresentados possamos em primeiro lugar inferir sobre os estudos comparativos entre dois termos dialogismos e intertextualidade com seus encontros/desencontros no decorrer da exposição. Percebeu-se, portanto, que na origem o conceito de dialogismo de Bakhtin representava em muitos aspectos aquilo que se entende por intertextualidade em Eco. Entre os dois, porém, foi Kristeva que realmente cunhou o termo intertextualidade e lhe atribui uma conotação como entendida pela literatura pós-moderna. Apesar da sua origem em Bakhtin de diversas outras contribuições inclusive a de Kristeva a intertextualidade assume um sentido todo especial em Eco que na nossa interpretação é mais amplo, aberto, dinâmico quando inserido na poesia pós-moderna, no conceito de enciclopédia mundo, e na criatividade do leitor modelo.

Tendo em vista que esse estudo foi embasado em uma das obras mais intertextualidades da pós-modernidade conclui-se o esforço de Eco em encontrar rastros de semelhante em um romance ambientado no século XIV, portanto fim do medievo, com a intertextualidade contemporânea. A quaestio $^{32}$ medieval apresenta em muitos aspectos as habilidades do método intertextual uma vez que volta ao passado para dialogar com outros textos, mas em Eco o intertexto recebe a característica da ironia. Uma vez que o livro fala sempre de outros livros o autor mascarado se ambienta num espaço de mais conforto deixando o protagonismo para o leitor critico desfrutar as riquezas do labirinto intertextual; por outro lado os desfechos intertextuais são sempre apresentados pelo discurso dos personagens que em $\mathrm{O}$ Nome da Rosa cabe principalmente Guilherme de Baskerville.

Levando-se em conta o que foi apresentado no tópico segundo torna-se de vital importância o modo que Eco intente a intertextualidade nos diversos contextos literários e na cultura pós-moderna enfatizando sempre a função do leitor modelo, sem esquecer que a teoria da interpretação de Eco encontra-se atrelada, dentre outros, à semiótica nas perspectivas de Pierce e Saussure. Mas a relação intertextual se apresenta não apenas como uma ação dual de um texto com

\footnotetext{
32 A quaestio medieval, principalmente como entendida na Universidade de Paris e por Tomas de Aquino consistia em apresentar um problema depois buscar soluções em diversos textos e de diversas épocas possíveis colocando os prós e contra, por fim, tentar um resumo podendo ter ou não uma solução. Os seguintes métodos: lectio (aula), expositio (exposição), quaestio (explicação) e disputatio (debate) ULLMANN (2000).
} 
outro texto, mas relaciona com um X quase inconsciente que é enciclopédia cultural. Por fim, tudo isso faz com que a intertextualidade se torne um caminho de volta ao passado sem o peso da tradição, de forma divertido e interligado ao presente com perspectiva de futuro sem vanguardismo exagerado.

\section{REFERÊNCIAS}

AGAZZI, Giselle; VINCI, Maria. O labirinto do mundo: intertextualidade e pós-modernismo em O Nome da Rosa de Umberto Eco. Literatura em debate, São Paulo, v.6, n 11, p. 80-98, dez. 2012.

BAKHTIN, Mikhail. Problemas da poética de Dostoievski. Tradução. Paulo Bezerra. $5^{a}$ ed. Rio de Janeiro: Forense Universitária, 2013.

BERNARDELLI, Andrea (org). La rete intertestuali: percorsi tra testi, discorso e imagine. Perugia: Morlacchi, 2010.

BEZERRA, P. Polifonia. In: Brait, B (org). Bakhtin: conceitos-chave. São Paulo: contexto, 2014. p. 191-200.

BRITO, Antônio. Obra aberta: teoria da vanguarda literária nas obras teórico-críticas de Umberto Eco. Campinas: Unicamp, 2006.

ECO, Umberto. O nome da rosa. Tradução de Aurora F. Bernardini e Homero Freitas de Andrade. $11^{\mathrm{a}}$ ed. Rio de Janeiro: Record, 2018.

Bompiani, 2019.

Il nome della Rosa; e appendice, postille a Il nome della rosa. Milano: Bompiani, 1977.

Casablanca, o la rinascita degli dei, in Dalla periferia dell'impero. Milano:

Lector in Fabula. Traducción de Ricardo Pochtar. $3^{\text {a }}$ ed. Barcelona: Lumem, 1993.

Pós-escrito a o Nome da Rosa. Tradução de Letizia Zini Antunes e Alvaro Lorencini. Rio de Janeiro: Editora Nova Fronteira, 1985.

Semiótica e filosofia da linguagem. Tradução de: Maria rosaria Fabris e José Luíz Fiorin. São Paulo: Ática, 1991.

Sobre os espelhos e outros ensaios. $3^{\mathrm{a}}$ ed. Rio de Janeiro: Nova Fronteira,

1989.

FARACO, Carlos Alberto. Linguagem e diálogo: as idéias lingüísticas do Círculo de

Bakhtin. Curitiba: Criar Edições, 2003. 
FRANCHI, Luigi. L'affare Eco: Sciascia, Il Nome della Rosa e l'ordine delle someglienza. Griseldaonline: Bologna, v.17, 2017-2018. Disponivel em:

$<$ https://www.academia.edu/36098633/L affaire Eco. Sciascia Il nome della rosa e 1 ordin e delle somiglianze>. Acesso em: 20 fev. 2020.

FIORIN, Jose Luiz. Interdiscursividade e intertextualidade. In BRAIT, Beth (ORG). Bakhtin outros conceitos-chave. São Paulo: contexto, 2006.

Introdução ao pensamento de Bakhtin. São Paulo: Ática, 2011.

FONDA, Enio. A tradução brasileira de O Nome da Rosa. Alfa UNESP, São Paulo, v: 30/31, p. $95-105,1987$.

JAMESON, Fredric. Pós-modernismo: a lógica cultural do capitalismo tardio. $2^{a}$ ed. São Paulo: 2007.

KNEZEVIC, Marana Cale. Il conceto de intertestualitá e "il nome della Rosa di Umberto Eco. Zagreb: 1988.

KRISTEVA, Julia. O texto do romance. Lisboa: Horizonte, 1984.

Semiótica: introdução à semanálise. Tradução. Lúcia Helena França Ferraz. $2^{\mathrm{a}}$ ed. São Paulo: Perspectiva, 2005.

LODGE, David, Introdução a O Nome da Rosa. In: ECO, Umberto. O nome da rosa. Tradução de Aurora F. Bernardini e Homero Freitas de Andrade. 11 a ed. Rio de Janeiro: Record, 2018.

PEIRCE, Charles Sanders. Semiótica. São Paulo: Perspectiva, 2005.

REALE, Geovanni; DÁRIO Anteseri. História da Filosofia: patrística e escolástica. (Tradução Ivo Storniolo), 4ª ed. São Paulo: Paulus, 2011.

SAUSURRE, Ferdinand de. Curso de linguística geral. São Paulo: 28ª ed. Cultrix, 2012.

SANTOS, Gerson. O leitor-modelo de Umberto Eco e o debate sobre os limites da interpretação. Kalíope, São Paulo, n. 2, p. 94-111 jul./dez., 2007.

TANI, Stefano. The doomed detective: The Contribution of the Detective Novel to Postmodern American and Italian fiction. Carbondale: Southern Illinois University Press, 1984.

ULLMANN, Reinholdo Aloysio. A Universidade Medieval. Porto Alegre: Editora PUCRS, 2000. 